\title{
Recapping Laminoplasty for Adult Low-Grade Isthmic Spondylolisthesis
}

\author{
Ahmed Saleh Shaker ${ }^{1 *}$ and Ahmed Hashem Amin ${ }^{2}$ \\ ${ }^{1}$ Orthopedic Department, Faculty of Medicine, Sohag University, Egypt \\ ${ }^{2}$ Orthopedic Department, Faculty of Medicine, Zagazig University, Egypt
}

\section{Abstract}

Study design: Prospective study.

Objectives of the study: To assess the results of recapping laminoplasty with posterior instrumentation and fusion in the management of adult low grade isthemic spondylolithesis.

Background: Isthmic spondylolisthesis is a condition where there is a translational displacement of the upper vertebral body compared to the lower one secondary to a defect in the pars interarticularis.

Methods: We treated10 patients, 3 men and 7 women with average age of 42.6 years using the technique of recapping laminoplasty and posterior transpedicular fixation and fusion. The mean vertebral slip was 33.5\% (14-47\%) preoperative, $6 \%(0-12 \%)$ direct postoperative and $7.4 \%(0-14 \%)$ after 1 year.

Results: At the latest follow up visit after 1 year 9 patients achieved fusion while 1 patient had non-union. The Oswestry disability index was mild in 8 patients and moderate in 2 patients.

Conclusion: Recapping laminoplasty can be used safely and effectively with anatomic reconstruction of the posterior structures for the management of adult low-grade isthmic spondylolisthesis.

Keywords: Recapping; Laminoplasty; Isthmic; Adult spondylolisthesis

\section{Introduction}

Isthmic spondylolisthesis is the most frequent type of spondylolisthesis [1] and occurs most often at L5-S1 [2]. Low back pain and leg pain are the usual symptoms of lowgrade isthmic spondylolisthesis. Several possible sources of pain in isthmic spondylolisthesis include instability at the defect, foraminal entrapment of a nerve root, disc herniation or disc degeneration at, above or below the slip, and hyperlordosis [3]. Conservative treatment is the first line of management including physiotherapy, braces, or pain medication. Surgical interference is preserved to cases with failure of conservative treatment or those with overt neurological deficits. Many surgical techniques have been advocated to deal with symptomatic isthmic spondylolisthesis; the main aim of the surgical techniques focused on spinal fixation and neural decompression [4]. Laminoplasty describes the process of increasing the space available for the spinal cord by reconstruction of the laminar arch via a posterior approach [5]. Thoracolumbar laminoplasty was first described by Raimondi [6] and it is well established in the management of spinal cord tumors [7], but it is not well known for isthmic spondylolisthesis. The aim of this study is to report our experience with recapping laminoplasty in combination with instrumented posterior fusion for the management of adult low grade ( $<50 \%$ slip) isthmic spondylolisthesis.

\section{Materials and Methods}

A total of 10 consecutive patients were surgically treated for adult

\begin{tabular}{|l|l|}
\hline Inclusion criteria & Exclusion criteria \\
\hline Age $>20$ years & High-grade spondylolisthesis \\
\hline $\begin{array}{l}\text { Low-grade isthmic spondylolisthesis } \\
(<50 \% \text { slip })\end{array}$ & Etiology other than isthmic spondylolisthesis \\
\hline $\begin{array}{l}\text { Failure of conservative treatment for } \\
\text { at least } 6 \text { months }\end{array}$ & Previous lumbar spine surgery \\
\hline & Presence of spinal infection or malignancy \\
\hline & Presence of other spinal deformity \\
\hline
\end{tabular}

Table 1: Inclusion and exclusion criteria for the study. low-grade isthmic spondylolisthesis. The inclusion and exclusion criteria for the study are listed in Table 1.

All patients have signed an informed consent explaining the operation and its possible complications. The pre-operative assessment included complete clinical and neurological examination, radiological assessment in the form of anteroposterior, standing lateral, oblique and dynamic lumbosacral X-rays and lumbosacral MRI (to assess disc condition and nerve root entrapment) and routine laboratory work. The amount of vertebral slip was measured from standing lateral radiographs and was calculated as the quotient of sagittal displacement and the sagittal length of the slipped vertebral body expressed in percent $[8,9]$.

\section{Surgical technique}

The operation was carried out through standard posterior midline approach. The defect of the pars interarticularis was identified and cleared of fibrous, cartilaginous and sclerotic tissue until healthy bone was exposed. Four pedicle screws were inserted in the intended level without final tightening; the supraspinous and interspinous ligaments between the lytic vertebra and the caudal one were cut in an oblique direction to be sutured later. The capsule of the inferior facet joints of the lytic vertebra were removed bilateral. After complete flavectomy en-bloc separation of the lamina together with the inferior articular processes of the lytic vertebra was done and reflected cranially with the supraspinous and interspinous ligaments maintained attached to the cranial vertebra. The nerve roots were decompressed and any lateral recess stenosis was

*Corresponding author: Ahmed Saleh Shaker, Orthopedic Department, Faculty of Medicine, Sohag University, 82524 Sohag, Egypt, Tel: +201064306080; Fax +20934602963; E-mail: asaleh1975@yahoo.com

Received February 19, 2014; Accepted March 13, 2014; Published March 16 2014

Citation: Shaker AS, Amin AH (2014) Recapping Laminoplasty for Adult LowGrade Isthmic Spondylolisthesis. J Spine 3: 160. doi:10.4172/2165-7939.1000160

Copyright: ( 2014 Shaker AS, et al. This is an open-access article distributed under the terms of the Creative Commons Attribution License, which permits unrestricted use, distribution, and reproduction in any medium, provided the original author and source are credited. 
managed. The facet joints were decorticated by high speed bur together with the laminae and transverse processes of the affected vertebra and the caudal one. Small moist gauze was used to protect the dura during burring. Particular attention was paid in order not to injure the superior facet joints. The retracted structures were repositioned followed by final tightening of the pedicle screws and insertion of the rods which help fixation of the loose lamina, the interspinous ligaments were sutured back, (Figure 1). In case of deficient interspinous ligament we use stainless steel suture to fix the spinous process of the slipped vertebra to the caudal one. Cancellous bone autograft harvested from the posterior iliac crest was carefully inserted in the pars defects and onto the surfaces of the decorticated facet joints, laminae and transverse processes. Parentral antibiotics were administered half an hour preoperative and for 5 days postoperative. Non-narcotic analgesics were used as indicated for pain control and tapered gradually. All patients were discharged on the 3rd postoperative day. Postoperative plain X-ray was done, and all patients started gradual ambulation without Lumbosacral support on the second postoperative day.

All patients were evaluated both clinically and radiologically in the outpatient clinic at 2 weeks, three, six and twelve months. The Oswestry disability index (ODI) questionnaire (9) and Lumbosacral CT to evaluate fusion were also done in the latest visit at one year (Figure 2).

\section{Results}

Relevant demographic data, fusion level and symptoms are shown in Table 2. The study included 10 patients, 3 men and 7 women. The average age of the patients was 42.6 years (range $28-55$ years). The mean operation time was $122 \mathrm{~min}$ (range 90-160 min); the intraoperative blood loss was $237 \mathrm{ml}$ (range 150-350 ml). The operated segments included L4-5 in 2 patients and L5-S1 in 8. The mean vertebral slip was $33.5 \%$ (14-47\%) preoperative, $6 \%$ (0-12\%) direct postoperative and 7.4\% $(0-14 \%)$ at the latest follow up. 9 patients achieved successful fusion as confirmed by CT at the latest follow up visit at 1 year and 1 patient had non-union. There was no metal failure and no loosening of implants. The Oswestry disability index one year postoperative was mild in 8 patients and moderate in 2 patients, one of whom was the patient with non-union. There was no postoperative neurological deficit, 3 patients had bone graft donor site pain which persisted more than 3 months but improved later. No other complications were detected.

\section{Discussion}

Surgical treatment of isthmic spondylolisthesis is reserved for symptomatic cases that failed conservative treatment or developed neurological deficit. There are different methods for the management of isthmic spondylolisthesis including decompression without fusion [10], posterolateral fusion (PLF) [11], instrumented posterior lumar interbody fusion (PLIF), anterior lumar interbody fusion (ALIF) or $360^{\circ}$ circumferential fusion [12]. There are 2 problems facing the surgeon performing posterior decompression and fusion, first the posterolateral region of the spine is one of the more challenging fusion environments because of the large gap that must be spanned by bone, the relatively poor vascularity of this region, the tensile stresses present in this region of the spine, and the presence of motion when the fusion is performed without supplemental internal fixation [13]. Second is the development of epidural fibrosis. Patients with epidural fibrosis experience radicular pain 3.2 times more frequently than those without it [14], furthermore the presence of epidural fibrosis makes surgical dissection difficult and revision surgery bears a high risk of intraoperative complications (e.g., bleeding, nerve root lesions and dural tears). The current technique
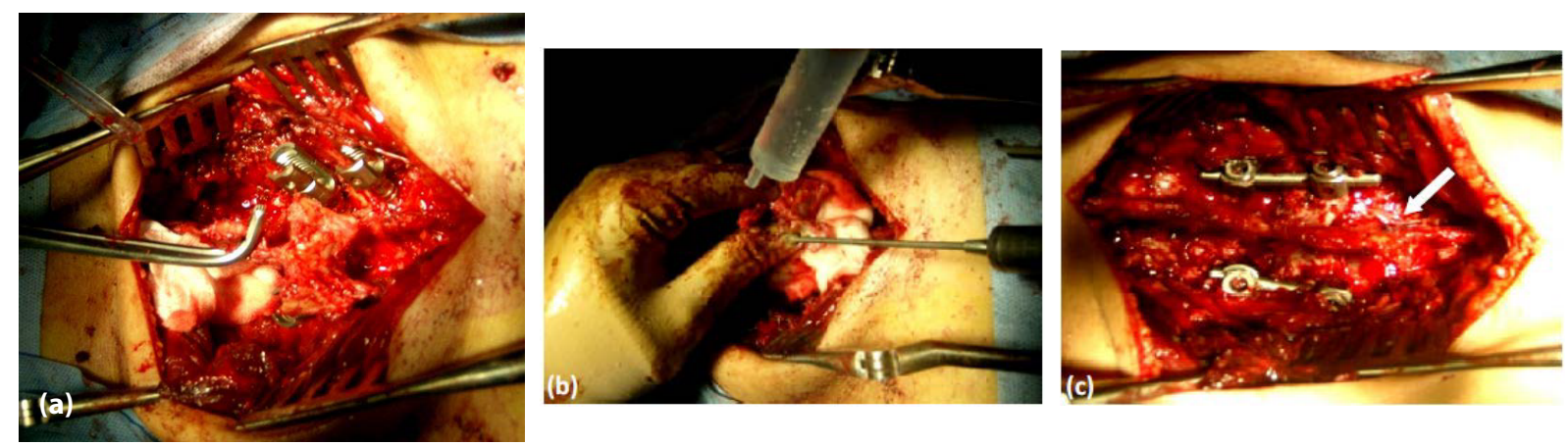

Figure 1: Operative technique, (a) En-bloc separation of the lamina (b) Facet decortication (c) Repositioning of the retracted structures, the white arrow shows suturing of interspinous ligaments.

\begin{tabular}{|c|c|c|c|c|c|c|c|}
\hline \multirow{3}{*}{ No. } & \multirow{3}{*}{ Sex } & \multirow{3}{*}{ Age $(Y)$} & \multirow{3}{*}{ Fusion level } & \multicolumn{3}{|c|}{ Preoperative symptoms } & \multirow{3}{*}{$\begin{array}{c}\text { Duration o } \\
\text { symptoms } \\
\text { (m) }\end{array}$} \\
\hline & & & & \multirow[t]{2}{*}{ Low back pain } & \multicolumn{2}{|c|}{$\begin{array}{l}\text { Lower limb } \\
\text { pain }\end{array}$} & \\
\hline & & & & & $\mathbf{R}$ & $\mathbf{L}$ & \\
\hline 1 & $\mathrm{~F}$ & 55 & L5-S1 & + & - & + & 60 \\
\hline 2 & M & 43 & L5-S1 & + & - & + & 36 \\
\hline 3 & $\mathrm{~F}$ & 54 & L5-S1 & + & + & + & 66 \\
\hline 4 & $\mathrm{~F}$ & 34 & L4-5 & + & - & + & 24 \\
\hline 5 & M & 28 & L5-S1 & + & - & - & 18 \\
\hline 6 & $\mathrm{~F}$ & 42 & L5-S1 & + & + & - & 48 \\
\hline 7 & $\mathrm{~F}$ & 56 & L4-5 & + & + & + & 54 \\
\hline 8 & M & 31 & L5-S1 & + & - & + & 30 \\
\hline 9 & $\mathrm{~F}$ & 45 & L5-S1 & + & + & - & 20 \\
\hline 10 & $\mathrm{~F}$ & 38 & L5-S1 & + & - & + & 12 \\
\hline
\end{tabular}

Table 2: Demographic data, fusion level and symptoms. 
Citation: Shaker AS, Amin AH (2014) Recapping Laminoplasty for Adult Low-Grade Isthmic Spondylolisthesis. J Spine 3: 160. doi:10.4172/21657939.1000160
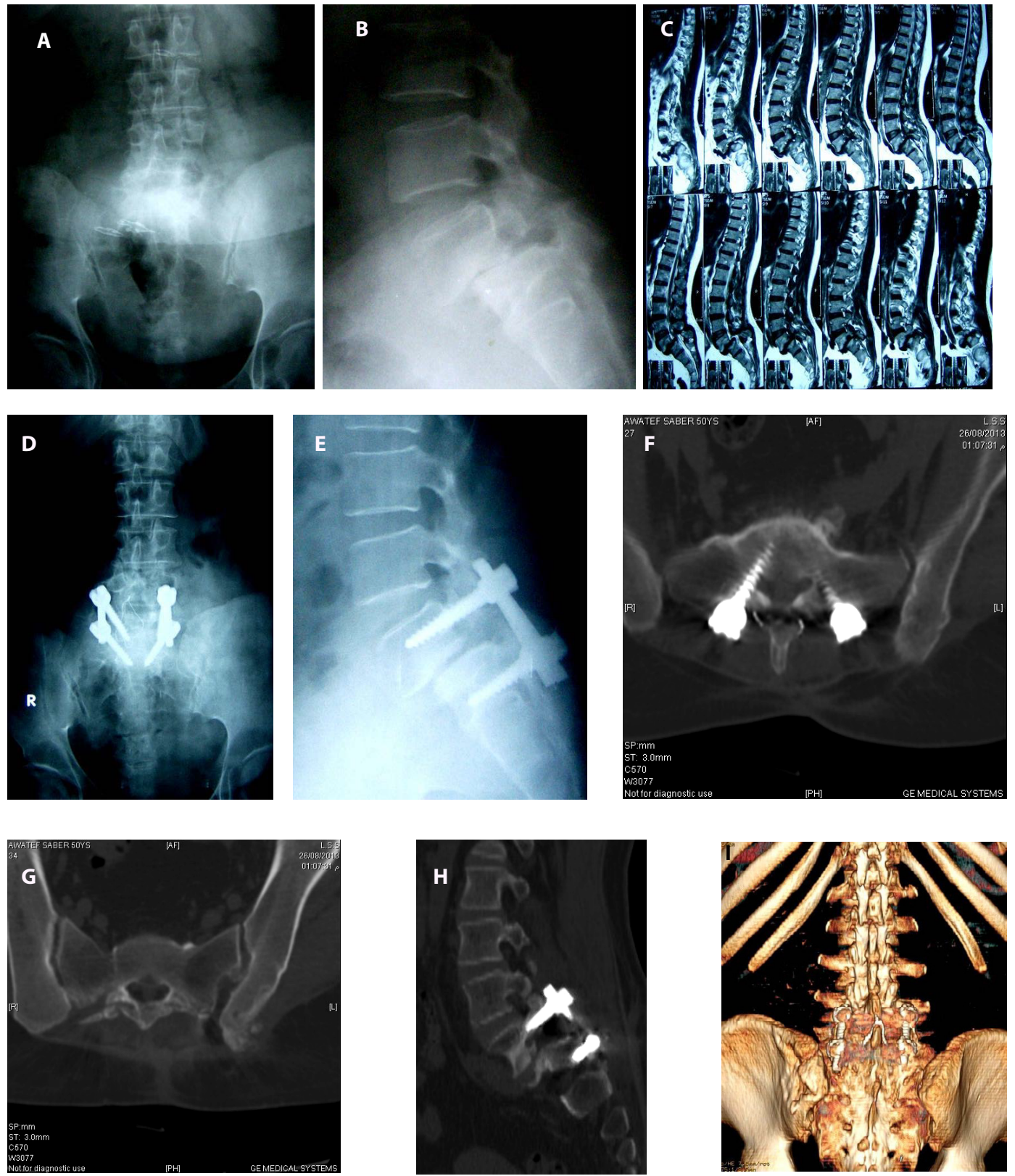

Figure 2: 55 years old lady, with low back pain not responding to medical treatment for more than 2 years and intermittent claudication pain (a and b) Preoperative X-ray.

(c) Preoperative MRI showing entrapment and kinking of the dural sac.

(d and e) Postoperative X-ray 1 year after surgery and CT showing fusion at (f) pars defect, (g) inferior facet joints, (h and i) between the laminae and transverse processes of both vertebrae.

addressed both problems; first this technique provides wider surface area for fusion including the retained laminae, spinous processes and facet joints together with the transverse processes which enhances fusion, second recapping laminoplasty allows good access for adequate spinal canal decompression and foraminotomy while maintaining the integrity of posterior structures which decreases epidural fibrosis [15] and facilitates revision surgery.

We found that PLIF was not necessary to get good results but on the other hand PLIF increased the intraoperative complications including dural tears, graft displacement, neurologic deficit and extensive bleeding from the venous plexus [16]. Furthermore PLIF does not provide advantages in terms of mechanical stability and fusion rate (pseudarthross incidence: $3.6 \%$ Versus $4.6 \%$ for PLF) [17]. In the current study, vertebral slip reduction was maintained after 1 year as compared to $360^{\circ}$ fusion [18]. Various rates for posterior lumbar fusion between 77 and 95\% [19] have been described. Our fusion rate was $90 \%$. The functional outcome of the patients assessed by Oswestry Disability Index (ODI) was mild in $80 \%$ and moderate in $20 \%$ of cases which is comparable to that of Audat et al. [20]. Although 3 patients had bone graft donor site pain but the pain gradually improved with no persistent complaint and no other complications were noted.

\section{Conclusion}

Recapping laminoplasty in combination with posterior 
Citation: Shaker AS, Amin AH (2014) Recapping Laminoplasty for Adult Low-Grade Isthmic Spondylolisthesis. J Spine 3: 160. doi:10.4172/21657939.1000160

instrumentation and fusion can be used safely and effectively for the management of adult low-grade isthmic spondylolisthesis. We consider our results encouraging, although the follow-up time is relatively short and the study group was small.

\section{References}

1. Möller H, Hedlund R (2000) Instrumented and noninstrumented posterolateral fusion in adult spondylolisthesis--a prospective randomized study: part 2. Spine (Phila Pa 1976) 25: 1716-1721.

2. Wiltse LL, Hutchinson RH (1964) Surgical treatment of spondylolisthesis. Clin Orthop Relat Res 35: 116-135.

3. Kaneda K, Satoh S, Nohara Y, Oguma T (1985) Distraction rod instrumentation with posterolateral fusion in isthmic spondylolisthesis. 53 cases followed for 18-89 months. Spine (Phila Pa 1976) 10: 383-389.

4. Jacobs WC, Vreeling A, De Kleuver M (2006) Fusion for low-grade adult isthmic spondylolisthesis: a systematic review of the literature. Eur Spine J 15: 391402.

5. Yucesoy K, Sonntag VK (2000) Terminology confusion in spinal surgery: laminotomy, laminoplasty, laminectomy. J Neurosurg 92: 371.

6. Raimondi AJ, Gutierrez FA, Di Rocco C (1976) Laminotomy and tota reconstruction of the posterior spinal arch for spinal canal surgery in childhood. J Neurosurg 45: 555-560.

7. Kawahara N, Tomita K, Shinya Y, Matsumoto T, Baba H, et al. (1999) Recapping T-saw laminoplasty for spinal cord tumors. Spine (Phila Pa 1976) 24: 13631370.

8. Laurent LE, Einola S (1961) Spondylolisthesis in children and adolescents. Acta Orthop Scand 31: 45-64.

9. Fairbank JC, Couper J, Davies JB, O'Brien JP (1980) The Oswestry low back pain disability questionnaire. Physiotherapy 66: 271-273.

10. Herron LD, Trippi AC (1989) L4-5 degenerative spondylolisthesis. The results of treatment by decompressive laminectomy without fusion. Spine (Phila $\mathrm{Pa}$ 1976) 14: 534-538

11. Dehoux E, Fourati E, Madi K, Reddy B, Segal P (2004) Posterolateral versus interbody fusion in isthmic spondylolisthesis: functional results in 52 cases with a minimum follow-up of 6 years. Acta Orthop Belg 70: 578-582.

12. Wenger M, Sapio N, Markwalder TM (2005) Long-term outcome in 132 consecutive patients after posterior internal fixation and fusion for Grade I and II isthmic spondylolisthesis. J Neurosurg Spine 2: 289-297.

13. Boden SD (1998) The biology of posterolateral lumbar spinal fusion. Orthop Clin North Am 29: 603-619.

14. Lubina ZI, Baranovic S, Karlak I, Novacic K, Potocki-Karacic T, et al. (2013) The grading model for the assessment of the total amount of epidural fibrosis in postoperative lumbar spine. Eur Spine J 22: 892-897.

15. Cabukoglu C, Güven O, Yildirim Y, Kara H, Ramadan SS (2004) Effect of sagittal plane deformity of the lumbar spine on epidural fibrosis formation after laminectomy: an experimental study in the rat. Spine (Phila Pa 1976) 29: 2242 2247.

16. Brantigan JW, Steffee AD, Lewis ML, Quinn LM, Persenaire JM (2000) Lumbar interbody fusion using the Brantigan I/F cage for posterior lumbar interbody fusion and the variable pedicle screw placement system: two-year results from a Food and Drug Administration investigational device exemption clinical trial. Spine (Phila Pa 1976) 25: 1437-1446

17. Barbanti Bròdano G, Lolli F, Martikos K, Gasbarrini A, Bandiera S, et al. (2010) Fueling the debate: Are outcomes better after posterior lumbar interbody fusion (PLIF) or after posterolateral fusion (PLF) in adult patients with low-grade adult isthmic spondylolisthesis? Evid Based Spine Care J 1: 29-34.

18. Spruit M, Pavlov PW, Leitao J, De Kleuver M, Anderson PG, et al. (2002) Posterior reduction and anterior lumbar interbody fusion in symptomatic lowgrade adult isthmic spondylolisthesis: short-term radiological and functional outcome. Eur Spine J 11: 428-433.

19. Carragee EJ (1997) Single-level posterolateral arthrodesis, with or without posterior decompression, for the treatment of isthmic spondylolisthesis in adults. A prospective, randomized study. J Bone Joint Surg Am 79: 1175-1180.

20. Audat ZM, Darwish FT, Al Barbarawi MM, Obaidat MM, Haddad WH, et al. (2011) Surgical management of low grade isthmic spondylolisthesis; a randomized controlled study of the surgical fixation with and without reduction. Scoliosis 6: 14. 